REVISTA DE GESTÃO E SECRETARIADO

MANAGEMENT AND ADMINISTRATIVE

PROFESSIONAL REVIEW

ISSN: 2178-9010
Revista GeSec

São Paulo, SP, Brasil

v. 11, n. 3, p. 1-26

set/dez 2020

DOI: http://dx.doi.org/10.7769/gesec.v11i3.1091

\title{
Assédio moral sutil em uma organização pública do poder legislativo
}

\section{Subtle moral harassment in a public organization of the Legislature}

\author{
Paula Fernandes Furbino Bretas ${ }^{1}$ \\ Henrique Luiz Caproni Neto ${ }^{2}$ \\ Marcos Moura-Paula ${ }^{3}$
}

\begin{abstract}
Resumo
Objetivou-se compreender o que os trabalhadores de uma organização do Poder Legislativo percebem como práticas de assédio moral e identificar práticas que favoreçam a ocorrência e combatam o assédio moral na percepção deles. Amplia-se, assim, o estudo para além de universidades e órgãos do Poder Judiciário, que têm sido as organizações mais recorrentes nas análises. Os dados primários foram coletados por meio de um questionário enviado por e-mail e foi feita análise de conteúdo. Como principais achados de pesquisa, tem-se que os trabalhadores não identificam a característica de reiteração no conceito de assédio, o que nos faz reconhecer o conceito de violência interpessoal, e que um grande desafio se relaciona à dificuldade de se comprovar situações de boicotes e silenciamentos, isto é, de assédio moral sutil. Outro achado importante se refere ao fato de os pesquisados relacionarem a cultura na organização com a ocorrência do assédio. Sugerimos que a estabilidade e a dificuldade de mobilidade podem ser fatores influenciadores no fenômeno do assédio nessa organização. Concluímos que práticas violentas sutis muitas vezes estão em um espectro de maior discricionariedade do gestor e podem ser confundidas com autonomia gerencial, tornando normalizadas ações que podem estar adoecendo trabalhadores. E que quanto maior essa discricionariedade, acompanhada por uma cultura organizacional repressora, maior é a dificuldade de comprovação do assédio moral que ocorre de forma sutil.
\end{abstract}

Palavras-chaves: Assédio Moral. Assédio Sexual. Organização Pública. Violência interpessoal.

\begin{abstract}
The aims of this article was to understand what the workers form a Legislature's public organization perceive as practices of moral harassment and to identify the practices that favored the occurence of and the combat to moral harassment by the perception of the aformentioned workers. Therefore, we broaden the study of moral harassment beyond universities and Judiciary settings, which has been the most recurrent organizations in the analysis. The primary data was colleted through a questionaire sent by e-mail and analyzed

\footnotetext{
${ }^{1}$ Mestre em Administração, Docente no Instituto Federal de Brasília (IFB).

${ }^{2}$ Mestre em Administração, Administrador na Universidade Federal de Juiz de Fora (UFJF).

${ }^{3}$ Mestre em Administração, Docente no IFB.
} 
through Bardin's content analysis. As the research main results, we pointed out that workers do not recognize the reiteraton character of the moral harassment, which makes us acknowledge the concept of interpersonal violence, and that there is a great challenge related to the difficulty in proving boycott and silencing situations, that is, the subtle moral harassment. Besides that, it is important to highlight that the respondents have related the culture of the organization to the moral harassment occurrence. We suggest that the stability in the job and the difficulty of moving across departments might be the influencing factors of the moral harasment in this particular organization. Our main conclusions are twofold. Firstly, the subtle practices of violence are most of the time a spectrum of the managers discretion, which is also confused to managerial autonomy, making actions that might be getting workers sick normalized. Secondly, the greater the manager's discretion, accompanied by a repressive organizational culture, the greater the difficulty in proving the moral harassment occurring in a subtle way.

Keywords: Interpersonal Violence. Public Organization. Moral Harassment. Sexual Harassment.

\section{Introdução}

Como um fenômeno global, a violência laboral prejudica aqueles que estão envolvidos diretamente nela, bem como suas organizações. Isso justifica atenção acadêmica e prática voltadas ao assédio moral no intuito de desenvolver mecanismos para lidar com este fenômeno, tendo em vista que o assédio moral não deve ser pensado somente no âmbito individual, mas também como um episódio envolto por discursos gerencialistas e capitalistas de uma gestão intensificada do desempenho nas organizações (Harrington, Warren, \& Hayner, 2015).

O assédio moral no trabalho afeta trabalhadores no mundo todo, de organizações privadas e públicas. No Brasil, desde 2017, tem havido uma diminuição das formalizações dos casos de assédio de acordo com levantamento do Tribunal Superior de Trabalho [TST]. Em 2016, os processos referentes a assédio moral representavam 10,4\% do total de processos novos formalizados. Em 2019, esse número caiu para 5,4\%. Poder-se-ia pensar que os casos diminuíram, mas a Confederação Nacional dos Trabalhadores no Serviço Público Federal alerta que as queixas informais são frequentes. E a Associação Nacional dos Magistrados do Trabalho acredita que a reforma trabalhista, ao transferir para o trabalhador o ônus dos custos das causas perdidas, pode ter inibido as formalizações que começaram a ter queda no segundo semestre de 2017 (Batista, 2019).

Em 2019, entendendo a importância da temática, a Câmara dos Deputados aprovou legislação que tramitava desde 2001 para criminalizar o assédio moral. Atualmente, o projeto se encontra em discussão no Senado Federal (Câmara dos Deputados, 2019), o que demonstra 
a atualidade e a relevância do fenômeno, que vem sendo preocupação de pesquisadores há pelo menos quatro décadas.

$\mathrm{O}$ assédio moral foi incluído nas agendas de pesquisas de várias áreas. Em uma busca do termo "assédio moral" no portal Scielo, é possível encontrar estudos nas Ciências da Saúde, Ciências Sociais Aplicadas, Ciências Humanas, Engenharias e Multidisciplinar. Já o assédio moral no trabalho vem sendo estudado a partir da década de 1980 (Vasconcelos, 2015). Sayer (2007) lembra que ele representa a instância mais severa de negação da dignidade no ambiente de trabalho, pois ela envolve respeito, confiança, autonomia, equidade e seriedade. Já Wang, Bowling, Tian, Alarcon e Kwan (2018) ressaltam que a maioria dos estudos estão voltados à análise da duração e frequência do assédio, mas que seria necessário considerar também os níveis de intensidade, já que algumas formas de assédio são mais intensas do que outras.

Monteiro (2013) evidenciou a existência de elevados números de afastamentos por transtornos mentais e comportamentais mesmo em organizações públicas que apresentam condições empregatícias favoráveis comparadas às empresas privadas. Observa-se que o trabalho nas organizações públicas é diferente do das empresas, o que não reduz o risco de adoecimento no trabalho. Logo, é possível inferir que o assédio é visto como um dispositivo de afastamentos por adoecimento psíquico no trabalho.

Acreditamos que, de modo semelhante ao apontado por Monteiro (2013), as organizações do Poder Legislativo apresentam salários mais altos comparados a outras organizações públicas, como já apontado em reportagens de jornais de grande circulação, como "O Globo" e "Correio Brasiliense". E as pesquisas sobre assédio moral em organizações públicas são geralmente realizadas em universidades (Petri, Severo \& Guimarães, 2015) e no Poder Judiciário (Corrêa \& Carrieri, 2004; Pooli \& Monteiro, 2018). Mendonça, Santos e Paula (2018), ao estudarem o estado da arte da pesquisa no Brasil sobre assédio moral, identificam uma lacuna no campo, que se refere à escassez de trabalhos com gestores públicos que explore a ocorrência do fenômeno nas organizações públicas.

Essas duas lacunas, relacionadas à intensidade do assédio e às organizações públicas como objeto empírico de estudo, justificam a realização desta pesquisa que visou responder ao seguinte problema: como o assédio moral é percebido pelos trabalhadores na organização pública Alfa? Objetivou-se compreender o que os trabalhadores de uma organização do Poder Legislativo percebem como práticas de assédio moral e identificar práticas que favoreçam a ocorrência e combatam o assédio moral na percepção deles. 


\section{Referencial Teórico}

\subsection{Assédio moral no trabalho}

Freitas (2001) lembra que o tema do assédio em si não é novo, o que se tornou novo foi sua denúncia. Embora Leymann (1996) esteja entre os pioneiros no estudo do assédio (mobbing) no trabalho (Pinto \& Paula, 2013), temos o modelo de Hirigoyen como o mais difundido no Brasil (Heloani \& Barreto, 2015).

O assédio moral pode ser definido como:

toda e qualquer conduta abusiva, manifestando-se, sobretudo por comportamentos, palavras, atos, gestos, escritos que possam trazer danos à personalidade, à dignidade ou à integridade física ou psíquica de uma pessoa, pôr em perigo o seu emprego ou degradar o ambiente de trabalho (Hirigoyen, 2001, p. 65).

O que o diferencia de um conflito "normal" no ambiente de trabalho não é necessariamente o que ou como foi feito, mas, sim, a frequência e longevidade do que foi feito, o seu caráter repetitivo ou contínuo (Salin, 2003). Freitas (2001) faz ainda uma ligação do assédio moral ao assédio sexual (crime tipificado no Código Penal Brasileiro), pois o primeiro pode conduzir ao segundo. Para caracterizar o assédio sexual, Freitas (2001) o difere de um convite constrangedor, já que o convite, por mais embaraçoso que seja, pode ser recusado. Portanto, o assédio sexual estaria mais ligado a uma intimação, uma ação em que se tenta acuar o outro, do que a um convite. Assim, “o que de fato é proposto no assédio é uma relação sexual para evitar inconvenientes na relação de trabalho" (Freitas, 2001, p. 14).

Ramos (2013) faz o raciocínio inverso ao de Freitas (2001) ao afirmar que o assédio sexual pode conduzir ao assédio moral. Uma vez que haja recusa à relação sexual, o sujeito agressor expõe a vítima à violência psicológica no intuito de desestabilizá-la e isolá-la. Nesse sentido, Freitas (2001) nomeia como perversão moral o fato de o agressor engrandecer-se com o rebaixamento do outro, sem sentir nem culpa nem sofrimento. Freitas (2001) ainda afirma que tal fato é presente no cotidiano, mas que não se ousa falar em perversidade.

Nunes, Tolfo e Nunes (2014) buscaram compreender os efeitos sofridos por observadores de agressões, usualmente colegas da própria vítima, que podem apresentar como efeitos a insatisfação com o trabalho e sintomas de estresse. Pode-se dizer que os autores inovaram no desenvolvimento conceitual do assédio moral, pois saíram do eixo da violência, que "aborda a caracterização da ocorrência, identificando vítimas, perfil de agressores, consequências, fatores influenciadores e demais" (Nunes, Tolfo \& Nunes, 2014, p. 167). 
Entretanto, essa caracterização em diferentes situações contextuais ainda se faz importante, visto que o tema é silenciado nas organizações.

\subsection{Características do assédio moral}

Mesmo o assédio moral não sendo regulamentado como crime, existem algumas caracterizações possíveis do fenômeno para que uma vítima possa ajuizar uma ação na Justiça, posto que o assédio atenta contra a dignidade humana (Ramos, 2003). Os quatro elementos constitutivos são: a conduta abusiva do assediador, a natureza psicológica da conduta, o prolongamento da conduta ofensiva no tempo e a finalidade de exclusão da vítima. Além disso, ele pode ser classificado em quatro tipos quanto à titularidade do agressor e ao nível hierárquico: horizontal, vertical ascendente, vertical descendente e misto (Hirigoyen, 2001; Freitas, 2001; Ramos, 2013).

O assédio moral horizontal é aquele praticado pelos próprios colegas da vítima, estando ambos, agressor e vítima, no mesmo nível hierárquico. Ao tentar nivelar os indivíduos em um grupo podem surgir problemas com as diferenças, devido à existência de preconceitos diversos como racial, sexual, religioso, político ou mesmo inveja por beleza, juventude, competência, riqueza, qualidades sociais etc. (Hirigoyen, 2001; Freitas, 2001; Ramos, 2013). É comum que as agressões e discriminações ganhem tom de deboche ou humor (Irigaray, Saraiva \& Carrieri, 2010) e sejam toleradas na organização, principalmente naquelas em que a cultura organizacional se baseia fortemente em piadas e brincadeiras (Salin, 2003).

O assédio moral vertical ascendente é aquele praticado por um subordinado contra seu superior hierárquico. Os subordinados, ao não cumprir ordens do superior, tentam remover sua autoridade e o mesmo se sente desacreditado perante sua função de liderança, afetando sua autoestima. Está relacionado, geralmente, às mesmas questões do assédio moral horizontal, sendo, contudo, menos frequente (Hirigoyen, 2001; Freitas, 2001; Ramos, 2013).

$\mathrm{O}$ assédio moral vertical descendente é aquele praticado pelo superior hierárquico contra seu subordinado. É o mais frequente dos quatro tipos de assédio e pode ser considerado o mais preocupante, pois as consequências psicológicas ou físicas são piores para a parte mais frágil da relação. A vítima sente-se isolada pelas humilhações e constrangimentos a que é submetida sob a tutela do poder hierárquico. Muitas vezes, por medo de perder o emprego, ela e os colegas ficam em silêncio. Pode haver também uma postura do assediado de mostrar que é capaz, o que o leva a trabalhar cada vez mais e com mais intensidade (Heloani \& Barreto, 2015; Hirigoyen, 2001; Freitas, 2001; Ramos, 2013).

Revista Gestão e Secretariado (GeSec), São Paulo, SP, v. 11, n. 3, set/dez, 2020, p. 1-26. 
$\mathrm{O}$ assédio moral misto, por fim, é aquele praticado tanto pelo superior hierárquico quanto pelos colegas. É uma mistura dos assédios vertical descendente e horizontal e ocorre, geralmente, em ambientes de trabalho muito competitivos. Pode-se dizer que a vítima se encontra na posição de "bode expiatório", passando a ser considerada culpada por tudo que se passa de errado na organização. É um fenômeno de efeito grupal no qual os subordinados tendem a seguir a mesma opinião/comportamento do líder (Hirigoyen, 2001; Freitas, 2001; Ramos, 2013).

Heloani e Barreto (2015) elencam ainda cinco características comuns do assédio moral. A primeira diz respeito a reduzir a capacidade de a vítima se comunicar adequadamente com os outros e com o próprio assediador. A segunda: ações de assédio para evitar que a vítima mantenha contato social no trabalho, de forma que ela fique isolada e invisível a todos. A terceira: ações de assédio que visam desprestigiar ou impedir que o trabalhador mantenha sua reputação pessoal ou profissional; assim, calúnias, rumores e fofocas sobre a vida privada do assediado são espalhadas. A quarta gira em torno de conferir descrédito profissional ao assediado, de forma que ele não tenha acesso a tarefas condizentes com sua qualificação ou é exposto a atividades que lhe sobrecarregam de trabalho. Finalmente, a quinta envolve ações que visam afetar a saúde mental e psíquica da vítima por meio de, por exemplo, realização de trabalhos perigosos, ameaças e agressões físicas leves, insinuação de roubos.

Apresentadas as características que perpassam o fenômeno do assédio moral, é necessário compreender as possíveis consequências dele.

\subsection{Consequências do assédio moral}

As consequências do assédio moral podem ser analisadas em diversos níveis: individual, organizacional e social. No nível individual, elas podem ser psíquicas ou físicas, tais como ansiedade, apatia, cansaço, depressão, insônia, desconforto gástrico, irritabilidade, estresse, insegurança, tensão, prejuízos na memória e na concentração e melancolia (Pooli \& Monteiro, 2018; Ramos, 2013; Samnani, 2013), atingindo a personalidade, a identidade e a autoestima (Freitas, 2007). O assediado se sente humilhado e inferiorizado (Hirigoyen, 2001), com desenvolvimento de consequentes quadros depressivos ou até mesmo suicídio, já que o “assédio gera desordens na vida psíquica, social, profissional, familiar e afetiva do indivíduo" (Freitas, 2007, p. 5).

No nível organizacional, alguns efeitos nocivos são afastamentos por doenças e acidentes de trabalho, aumento do absenteísmo, aumento da rotatividade e dos custos de 
reposição, maior intenção de deixar a organização, queda da produtividade em função da queda do moral do grupo, diminuição da lealdade e do comprometimento, custos judiciais relativos a possíveis indenizações, reforço de comportamentos negativos de indivíduos devido à impunidade (Freitas, 2007). Todos esses efeitos refletem na economia da organização, uma vez que os custos com pessoal aumentam (Ramos, 2013). Considere-se ainda que trabalhadores agressivos ocupando posições de liderança podem influenciar a organização a ter uma cultura mais agressiva, o que pode levar a um maior nível de assédio (Samnani \& Singh, 2012). Ademais, existem consequências indiretas para as organizações na área de Marketing, como aquelas ligadas à projeção de imagem negativa perante seus intervenientes (stakeholders), bem como na área de Gestão de Pessoas, como a dificuldade de recrutamento e retenção de talentos devido à exposição negativa (Freitas, 2007).

No nível social, o assédio gera consequências negativas, pois não se restringe a vida individual, afetando relações familiares e comunitárias com divórcios, abortos e riscos de suicídio, gerando custos ao Estado com saúde (hospitalizações, remédios subsidiados, longos tratamentos médicos), assistência e previdência social (acidentes de trabalho e incapacitação/aposentadoria precoce, licenças), além do desemprego, da perda do investimento realizado em educação e formação profissional e dos custos com processos judiciais (Freitas, 2007; Ramos, 2013; Samnani \& Singh, 2012). Soma-se a isso que os problemas econômicos enfrentados pelas organizações podem ser transferidos ao consumidor por meio do aumento dos preços de produtos (Freitas, 2007). Portanto, há um aumento do mal-estar no âmbito social.

\subsection{Desafios para combater o assédio moral}

Freitas (2007) elenca alguns desafios para que se possa prevenir ou mesmo eliminar a ocorrência de assédio. São eles:

a) Coragem e vontade política das chefias para reconhecer a possibilidade de ocorrência;

b) Disposição em apurar, coibir, punir os responsáveis sem exceções;

c) Criar instrumentos confiáveis para a denúncia e a apuração dos fatos;

d) Profissionais que sejam considerados como pessoas legítimas e imparciais para lidar com a atividade;

e) Prezar para que as denúncias não fiquem sem respostas.

Esses desafios são interdependentes entre si, já que essas ações isoladamente serão insuficientes para combater o assédio moral. Por exemplo, de nada adianta ter canais para denúncias como urnas anônimas se elas não forem apuradas; de nada adianta responder 
denúncias se os trabalhadores não sentem que os profissionais designados são pessoas imparciais e legítimas; de nada adianta expressar um discurso sobre a vontade de se combater o assédio se isso não se transformar em práticas e políticas, inclusive em punições. Assim, é preciso compreender que talvez seja necessária uma revisão de várias práticas muitas vezes já naturalizadas, incluindo as condições organizacionais (Rodrigues \& Freitas, 2014), e isso não é algo simples de se fazer. Nunes e Tolfo (2013) alertam para o fato de que as vítimas podem até comentar com colegas sobre a violência, mas a maioria ainda não formaliza denúncias, seja por sentimento de impotência por não acreditar que a denúncia irá solucionar a questão, seja por falta de provas devido à natureza sutil de algumas práticas hostis, ou mesmo por medo. Isso pode demonstrar o despreparo da gestão para lidar com os casos, bem como falta de estrutura na organização.

Soboll e Heloani (2008) não consideram que o assédio possui uma causalidade linear, como "mentes doentias" à procura de "vítimas indefesas". Os autores atentam para a necessidade de uma análise processual que considere o contexto organizacional, tendo em vista que a "doença pode ser da organização e não propriamente do indivíduo que apresenta os comportamentos 'inadequados"” (Soboll \& Heloani, 2008, p. 23)". Isso não significa a isenção de responsabilidades individuais, mas da necessidade de se pensar em possibilidades de assédio moral e de assédio organizacional, pois “a não diferenciação implica um tratamento generalizado que em nada contribuiu para a construção de estratégias efetivas de prevenção e enfrentamento" (Soboll \& Heloani, 2008, p. 24).

Nunes, Tolfo e Nunes (2014) identificaram que a percepção de alguns profissionais é de que a organização em que trabalham é insuficiente no combate ao assédio, mesmo possuindo instrumentos para denúncia. Esta não é apurada adequadamente e o agressor não sofre consequências de acordo com a gravidade da situação. Portanto, o assédio continua gerando efeitos nocivos ao ambiente de trabalho, repercutindo até mesmo na saúde do trabalhador que observa a violência e percebe que não existem ações para cessar as hostilidades e punir o agressor. Nessa direção, Harrington, Warren e Rayner (2015) alertam quanto à posição do setor de gestão de pessoas que, buscando muito mais exercer um papel de parceiro de negócios em busca de desempenho organizacional do que de defensor dos trabalhadores, acaba tendo como práticas: a falta de ação, a negação, a culpabilização da vítima e a cumplicidade com a gestão.

Diante das características, consequências e desafios para combater o assédio moral no trabalho, é necessária a discussão de algumas especificidades que diferenciam a ocorrência do fenômeno em organizações públicas. 


\subsection{Assédio moral nas organizações públicas e suas especificidades}

A primeira característica que salta aos olhos na diferença entre o assédio em organizações públicas e privadas se refere ao fato de não existir medo latente de ser demitido ou exonerado no setor público devido ao seu direito à estabilidade. Gediel e Mello (2015) fazem um estudo sobre a relação entre a estabilidade, a democracia e o assédio. Nesse sentido, o servidor público tem direito à estabilidade que visa garantir-lhe proteção na sua relação contratual com o Estado de forma que tenha condições igualitárias de trabalho e preveni-lo de sofrer discriminações. Além disso, protege o servidor da vontade do agente político, conferindo-lhe impessoalidade em sua função. Dessa forma, a estabilidade permite a participação ativa dos servidores públicos em atos de manifestação e negociação de interesses individuais e coletivos e garante a impessoalidade e igualdade no serviço público, ambos princípios democráticos. Portanto, o assédio afeta esse direito à estabilidade, na medida em que o restringe ou viola.

Algumas ações específicas no serviço público que podem ser configuradas como assédio são (Gediel \& Mello, 2015):

a) Condutas arbitrárias de comissões de avaliação de desempenho funcional em estágio probatório;

b) Decisões de alteração funcional (posto, local de trabalho, funções) que não tenham finalidade pública;

c) Práticas discriminatórias (idade, gênero, origem, cor da pele, características físicas);

d) Pressão por resultado, característica da transição do modelo de administração pública burocrático para o gerencial.

É possível observar que essas especificidades, principalmente as duas primeiras, que são típicas ações de hostilização no serviço público, geram dificuldades no combate ao assédio na administração pública. Em relação ao estágio probatório, o ônus da prova é do servidor público. Já em relação às decisões de alterações funcionais, elas podem ser facilitadas, uma vez que o modelo gerencial prevê maior autonomia para gestores.

Chapadeiro (2015) ainda elenca mais duas especificidades: no serviço público, o assediador também pode ser um servidor efetivo e, em casos de afastamento do servidor assediado, não se pode nomear ou fazer outro concurso para reposição de pessoal, uma vez que o assediado ocupa um cargo público e esses cargos são preenchidos mediante concurso. No primeiro caso existe previsão constitucional de processo administrativo para demissão de 
servidores. Em muitos casos, no entanto, ainda não há mecanismos legais para assistir o trabalhador assediado.

Além disso, o assédio moral no serviço público estaria mais ligado a disputas de poder do que à busca por produtividade, de forma que a cobiça e a inveja podem levar um indivíduo a tentar exercer controle sobre outrem para tirá-lo de seu caminho (Corrêa \& Carrieri, 2004). Pooli e Monteiro (2018, p. 348) argumentam que dentre as razões para uma maior ocorrência de assédio moral no serviço público estão o estilo de gestão/liderança (mais autoritário), o ambiente de mudanças que ocorrem de maneira repentina que geram medo, a predominância do estresse no ambiente de trabalho, a existência de conflitos não sanados, as "tarefas mal distribuídas e monótonas, a inadequação e/ou falta de treinamento para exercício de determinadas atividades e o sistema de avaliação de desempenho e estabilidade vigentes no setor público". Também podemos incluir o ideal gerencialista, que aumenta a discricionariedade das decisões do gestor, o qual vem sendo apropriado por organizações públicas, o impacto do neoliberalismo, bem como o caráter político que as envolve.

Por fim, Monteiro (2013) buscou desmistificar a ideia de que o adoecimento no trabalho esteja relacionado apenas às questões econômicas, como baixa remuneração, fragilidade dos vínculos de emprego, sobrecarga física do trabalho, entre outras questões características das relações de trabalho na iniciativa privada. Observou que mesmo em organizações públicas, que apresentam condições empregatícias favoráveis comparadas às empresas privadas, ainda assim existem elevados números de afastamentos por doenças relacionadas a transtornos mentais e comportamentais, incluindo sofrimentos relativos ao assédio moral.

\section{Metodologia}

Esta pesquisa se classifica como qualitativa, uma vez que se pretende uma proximidade com os sujeitos de pesquisa devido à natureza da temática e às relações de poder envolvidas no processo de pesquisa. As principais características que vão ao encontro desta pesquisa, justificando a escolha por tal abordagem, são: busca de fonte direta de dados em ambiente natural no qual o pesquisador possui proximidade; preocupação com descrição dos fenômenos observados privilegiando os significados em detrimento da simples preocupação com os resultados, dando, assim, ênfase na relação entre elementos e processos; número de elementos de estudo é pequeno; tipos e números de fontes de dados são geralmente vários e heterogêneos (Boaventura, 2004; Gonçalves \& Meirelles, 2004). 
Trata-se de um estudo realizado em uma organização pública do Poder Legislativo, localizada na Região Sudeste, aqui denominada Alfa. Possui cerca de 3.200 trabalhadores em diferentes vínculos funcionais, como servidores de carreira (com direito à estabilidade) e de recrutamento amplo (sem direito à estabilidade), sendo estes mais de $2 / 3$ do quadro funcional. Uma das autorias deste artigo trabalhou na organização estudada, tendo proximidade com o fenômeno e acesso direto aos sujeitos de pesquisa, facilitando a construção desse estudo. Ao observar que aconteciam recorrentes casos de assédio moral na organização, essa autoria começou a se questionar por que isso acontecia ali e como se dava o fenômeno considerando os diferentes setores. À princípio, poder-se-ia ter a ideia de que o problema se origina apenas de uma pessoa específica que ocupa cargo de chefia, mas ao observar a ocorrência em diferentes setores, a complexidade do assédio moral se delineava.

Já com essas inquietações, ao assistir uma palestra promovida pelo sindicado sobre assédio moral no trabalho, buscou-se realizar os primeiros contatos com possíveis interessados em participar da pesquisa, sendo majoritariamente servidores de carreira. É importante ressaltar que os servidores de recrutamento amplo dificilmente participam de reuniões, assembleias ou manifestações realizadas pelo sindicato e pela instância de representação de trabalhadores junto à gestão de pessoas.

No início, várias pessoas se prontificaram a participar do estudo ou a indicar outras pessoas a participarem, tendo sofrido ou não assédio. Contudo, quando se chegou no período da realização de entrevistas, algumas pessoas manifestaram o receio da participação. Assim, decidiu-se mudar a estratégia de produção de dados de entrevistas para questionários eletrônicos com questões abertas, para aumentar a privacidade dos sujeitos de pesquisa. Mesmo assim, algumas pessoas desistiram de participar ao longo do processo. Essa foi a maneira encontrada para superar um dos principais dificultadores da pesquisa: a indisposição das pessoas em falar do tema, principalmente por se tratar da organização na qual trabalham.

O questionário com 11 perguntas foi dividido em três partes: dados pessoais, percepção sobre o assédio moral e percepção sobre o combate ao assédio moral. As perguntas direcionavam o olhar para a organização em que trabalhavam naquele momento. A produção de dados aconteceu no primeiro semestre de 2018.

Para análise dos dados, utilizou-se a análise de conteúdo temática e qualitativa (Bardin, 2009). Desse modo, os dados tratados foram apresentados em conjuntos de categorias definidos a partir do corpus da pesquisa, buscando-se a semelhança de elementos dentro de um mesmo tema. As próprias perguntas delinearam a formação de algumas categorias. Contudo, a relação entre assédio moral e assédio sexual surgiu espontaneamente 
entre os sujeitos de pesquisa, o que motivou a criação de mais uma categoria, considerando que autores já haviam apontado para a importância dessa relação.

\subsection{Perfil dos/as respondentes}

Nesta pesquisa, foi considerado como público qualquer servidor da organização Alfa. Por acessibilidade, a pesquisa foi divulgada por e-mail de forma direcionada para alguns sujeitos participantes que manifestaram em contato anterior sobre o interesse em participar da pesquisa. Esses sujeitos também encaminharam para outros sujeitos seguindo a técnica bola de neve.

Os questionários foram encaminhados inicialmente para 10 pessoas que se dispuseram a participar após a palestra. Algumas delas disseram que encaminharam para outras pessoas que responderiam. Nesse grupo, havia pessoas-chave na organização, como participantes de um coletivo de mulheres, representantes que foram eleitos pelos trabalhadores, profissionais que atuavam no núcleo de saúde e na criação de ações para combate ao assédio moral, além de haver trabalhadores de diferentes setores. Percebendo o receio manifestado nas conversas pessoais, foi enviado e-mail com a seguinte informação:

Como estou buscando conhecer a percepção das pessoas que trabalham/trabalharam na organização sobre o assédio, meu universo é bem amplo, não se limitando a pessoas que tenham sofrido assédio. Estou buscando pessoas que possam ter ouvido falar, presenciado ou sofrido, efetivos ou não, na ativa ou aposentados.

A pesquisa é anônima e, por isso, estou fazendo as entrevistas online. Caso alguém queira participar, pode, por exemplo, enviar as respostas a vocês e vocês me reencaminham. Assim, não terei nem acesso à identificação das pessoas. Além disso, trocarei o nome da organização, dos setores e outras características que possam identificar a organização no trabalho final.

Não obstante, conforme descrito na Tabela 1, participaram da pesquisa 5 sujeitos:

\section{Tabela 1.}

Perfil dos/as respondentes

\begin{tabular}{|l|l|l|l|l|}
\hline Identificação & Tempo de trabalho na instituição & Idade & Vínculo & Setor \\
\hline R1 & 14 anos & 32 anos & Efetivo & 1 \\
\hline R2 & 9 anos & 41 anos & Efetivo & 2 \\
\hline R3 & 7 anos & 36 anos & Efetivo & 3 \\
\hline R4 & Não respondeu & Não respondeu & Não respondeu & 4 \\
\hline R5 & 9 anos & 35 anos & Efetivo & 1 \\
\hline
\end{tabular}

Fonte: elaborado pelos autores. 
Todos os sujeitos estão ativos e, para preservá-los, a informação sobre sexo/gênero foi omitida. Vale ressaltar o quão importante é a preservação do anonimato nesta pesquisa, a partir de uma história vivenciada no contexto da apresentação de parte do estudo. Na ocasião, o irmão do presidente da organização estudada estava na plateia, sem que os autores da pesquisa soubessem, e interrompeu a apresentação com a seguinte fala: "pode deixar que não vou contar para meu irmão que você está estudando a organização". Acreditamos que esse contexto é um importante dado de pesquisa na justificativa da falta de mais dados da organização ou dos sujeitos de pesquisa.

Como o tema da pesquisa é delicado por refletir relações de poder, é comum haver obstáculos no campo em relação ao número de respondentes, sendo esta uma das limitações deste estudo. Contudo, por se tratar de uma abordagem qualitativa, cuja amostra não é probabilística, objetiva-se descrever e analisar o fenômeno da percepção do assédio moral sem a preocupação em generalização de dados para todo o universo.

Depois de lidos e organizados, os dados foram analisados e classificados em sete categorias de conteúdo (Bardin, 2009) que serão detalhadas na próxima seção.

\section{Análise e discussão dos resultados}

Nesta seção, estão apresentados os resultados da pesquisa em sete subseções, buscando-se descrever em detalhes a percepção desses trabalhadores sobre o fenômeno do assédio moral na organização Alfa. Inicialmente, foi analisada a percepção sobre o conceito de assédio moral, pois se acredita que o primeiro passo para combate ao assédio moral é o seu reconhecimento. Na segunda subseção, foi considerada a percepção geral do assédio moral com os outros na organização, pois o estudo buscou não somente pessoas que se sentiram vítimas de práticas de assédio, mas qualquer trabalhador que pudesse identificar essas práticas na organização. Na terceira, o foco foi a percepção do assédio moral presenciado na organização, na tentativa de buscar compreender possíveis ações do ponto de vista dos observadores. Na quarta, a categoria que emergiu dos dados foi a relação entre assédio moral e assédio sexual, que não estava prevista como temática a priori. Na quinta, foi analisada a percepção sobre a própria vivência como vítima de assédio moral. Na sexta, foram compreendidas as práticas que favorecem a ocorrência do assédio moral na organização. Por fim, na sétima, foram discutidas as práticas de combate ao assédio moral na organização. 


\subsection{Percepção sobre o conceito de assédio moral}

As/os respondentes compreendem o conceito de assédio como uma prática que adoece, humilha, intimida, constrange, subjuga e diminui o outro:

Uma prática que adoece quem é vítima. Uma forma de trabalhar que persegue, subjuga, diminui, humilha e adoece o outro (R2).

É uma situação de constrangimento e humilhação que uma pessoa sofre (R4).

Entendo o assédio como a utilização de estruturas de poder para o constrangimento de pessoas (de suas liberdades, de sua autonomia e de seu bem-estar) em seus ambientes de trabalho - são práticas de abuso de poder. É um processo de inferiorização, constrangimento, diminuição e subjugação de alguém em virtude de sua posição hierárquica inferior ou de sua condição de vulnerabilidade (de identidade sexual e de gênero, condição étnica, racial ou social, idade, etc) (R5).

\section{Abordagem inadequada de alguém com relação à outra pessoa, intimidação, pressão sob determinada} entrega ou expectativa, falta de acordos claros, medo (R1).

Sofrer críticas injustas, ser coagido/a a certos comportamentos, ofensas que expõem o servidor e causem ofensa à sua integridade física ou psíquica (R3).

A percepção exposta coaduna com a conceituação de Freitas (2001) no sentido da humilhação, intimidação, constrangimento, subjugação e diminuição do outro. Também vai em direção à caracterização do assédio moral por meio de atitudes hostis no trabalho feita por Hirigoyen (2001). Nesse caso, a pressão, a falta de acordos claros e as críticas injustas podem ser relacionados com a deterioração proposital das condições de trabalho (criticar seu trabalho de forma injusta ou exagerada, retirar a autonomia da vítima, não lhe transmitir mais as informações úteis para a realização de tarefas, pressioná-la para que não faça valer seus direitos) e as ofensas podem ser relacionadas com o atentado contra a dignidade (utilizar insinuações desdenhosas para qualificar a vítima, espalhar rumores a seu respeito).

Nunes, Tolfo e Espinosa (2018) fizeram o questionamento sobre o que estudantes (sendo profissionais de diversas áreas) e servidores de uma universidade entendiam como assédio moral. Foram citados os termos humilhação, constrangimento, coação, intimidação, pressão e ofensa no âmbito das práticas hostis, o que se assemelha ao presente estudo. Contudo, os trabalhadores do legislativo expressaram alguns termos e expressões que não apareceram na universidade, como subjugação, diminuição, críticas injustas e prática que adoece. Essas palavras estão diretamente ligadas ao ato de alguém inferiorizar outra pessoa e demonstra a preocupação desses trabalhadores com a saúde mental. É importante ressaltar que entre os respondentes na pesquisa de Nunes, Tolfo e Espinosa (2018) também havia pessoas que atuavam no setor privado, cuja característica do assédio moral costuma ser mais evidente e durar menos. No caso desta pesquisa, o fato de os trabalhadores terem estabilidade e 
expectativa de trabalhar durante muitos anos na mesma organização pode influenciar nessa preocupação com a saúde mental quando conceituam o assédio moral.

Entretanto, pode-se observar que os/as participantes não mencionaram o caráter repetitivo do assédio moral. Segue outro relato:

Fui vítima de práticas de assédio onde trabalho pois deixei um calendário no qual participo do estúdio de [dança] e sofri comentários maldosos de colegas e Diretores. Tive que tirar da minha mesa pois foi considerado uma postura não profissional (R3).

O excerto acima corrobora a crítica feita por Pinto e Paula (2013) ao conceito de assédio de moral, pois o mesmo teria algumas limitações como a recursividade dos atos, bem como a intencionalidade do sujeito assediador e a preocupação com consequências pela ótica da gestão, desconsiderando que este sujeito é humano além de trabalhador, existem, portanto, outras esferas de sua vida afetadas quando sofre no trabalho. Pinto e Paula (2013) propõem o conceito de violência interpessoal:

a violência interpessoal advém do ato de agredir o sujeito física e/ou discursivamente e/ou por atitudes e/ou comportamentos prejudiciais, sejam estes propositais ou não. Tal manifestação de violência se desenvolve, necessariamente, durante a interconexão de duas ou mais pessoas, pontual ou recursivamente, no ambiente de trabalho, revelando-se como violência física, discursiva, fruto de atitudes ou derivada de comportamentos (p. 348).

Wang et al. (2018) enfatizam que os pesquisadores devem considerar que algumas formas de assédio são mais intensas do que outras, mesmo que não ocorram persistentemente, visando alcançar uma abordagem mais compreensiva do fenômeno no mundo do trabalho. Acreditamos, assim, que o conceito de violência interpessoal possa abarcar melhor as situações perversas nas organizações, não se limitando ao assédio moral que, muitas vezes, é difícil de ser conceituado, comprovado e até mesmo compreendido devido à sutileza dos atos.

\subsection{Percepção geral do assédio moral com os outros na organização}

Em relação à percepção geral do assédio moral praticado com os outros na organização, as/os respondentes relataram casos que ouviram falar, conforme os excertos:

Escuto depoimentos de colegas que se sentem perseguidos pelos gerentes de várias maneiras: com excesso de trabalho, com ausência de trabalho (o que faz a pessoa se sentir inútil), com estigmatização (fulano é preguiçoso, lento, estressado ou reclamão) ou com uma tentativa de fazer com que os subordinados pensem da mesma maneira que o chefe, ou seja, se enquadrem em sua visão institucional (R2).

Sonegação de informações, atribuição de tarefas inferiores, dificultar promoções (R3).

$\mathrm{Na}$ organização onde trabalho, é comum ouvir histórias de perseguição e de tratamento desigual de pessoas em virtude de seus ciclos de relacionamento, identidade sexual e de gênero ou cargo, de assédio sexual. Há pessoas que, aparentemente, por não corresponderem a expectativas de seus superiores, são tidas como loucas (R5). 
É possível identificar atitudes de deterioração proposital das condições de trabalho (Hirigoyen, 2001), como: a atribuição proposital e sistemática de tarefas inferiores às suas competências ("ausência de trabalho" e "atribuição de tarefas inferiores"), que lhe conferem descrédito profissional (Heloani \& Barreto, 2015); a não transmissão de informações úteis para a realização de tarefas ("sonegação de informações"); a ação de modo a impedir que a vítima obtenha promoção (“dificultar promoções”). Também estão presentes atitudes hostis caracterizadas como atentados contra a dignidade, como utilizar insinuações desdenhosas para qualificar a vítima ("estigmatização") e atribuir-lhe problemas psicológicos quando dizem que a vítima é doente mental ("são tidas como loucas").

Nos excertos de R2 e R5, é possível observar que o assédio pode acontecer quando o comportamento do subordinado não corresponde à expectativa do chefe. Nunes, Tolfo e Espinosa (2018) apontam que a incidência de abuso de poder é grande no setor público quando estudam universidades. Os excertos de R2 e R5 demonstram que o abuso de poder (ao querer fazer com que o funcionário pense como o chefe ou ao chamar de louco/a) é um tipo de ação que acontece como consequência ao medo de perder poder.

\subsection{Percepção do assédio moral presenciado na organização}

Para Freitas (2001), é comum que as pessoas que presenciam esses atos hostis, evidentes ou escondidos, não intervenham na situação. Nunes, Tolfo e Nunes (2014) buscaram compreender os efeitos sofridos por esses observadores que visualizaram agressões. Muitas vezes eram colegas da própria vítima e apresentaram como efeitos a insatisfação com o trabalho e sintomas de estresse. Nesta pesquisa, questionamos os/as participantes sobre terem presenciado alguma situação de assédio. Observe os excertos:

\footnotetext{
Uma das situações mais recorrentes [no meu local de trabalho] é ver colegas questionadores, ou seja, que questionam ordens superiores, serem estigmatizados, tanto pelo gerente quanto por outros da equipe como "piqueteiros", "cri-cri”, "reclamões" (R2).

Há casos em que o ocupante de um cargo busca inferiorizar, menosprezar determinados servidores em virtude do cargo que ocupam (num sentido de "mostrar o seu devido lugar"). [...] suas funções eram menosprezadas, os espaços que ocupavam na gerência eram delimitados, os demais servidores que ela considerava "superiores" tinham preferências em marcação de férias, de folgas, na ocupação de mesas no setor e tratamento desigual na concessão de folgas ou benefícios para participação em cursos, por exemplo. Também já presenciei colega de trabalho ser questionada a respeito das licenças médicas que havia tirado, numa ação clara de abuso de poder (R5).
}

Em todos os relatos, apesar de terem presenciado, as/os respondentes não relataram sobre sua ação, sentimento ou pensamento na ocasião, corroborando com Freitas (2001). Há que se considerar que às vezes as testemunhas não intervêm por temerem se tornar também 
vítimas (Freitas, 2001; Pate \& Beaumont, 2010). Houve uma exceção quando o caso presenciado se tratou de assédio sexual, conteúdo que será analisado no próximo tópico.

\subsection{Relação entre assédio moral e assédio sexual}

Apesar de não se tratar do foco da pesquisa, foram citados alguns casos de assédio sexual durante a entrevista sobre assédio moral. Para Freitas (2001), o assédio moral pode conduzir ao assédio sexual, pois "o que de fato é proposto no assédio é uma relação sexual para evitar inconvenientes na relação de trabalho" (Freitas, 2001, p. 14).

\footnotetext{
Já sofri situações específicas em que fui assediado/a sexualmente sem contato físico, mas com intimidações, piadas e sugestões quando eu era estagiário/a e no início da minha carreira como servidor/a efetivo/a; em ambos os casos com [chefes] (R1).
}

Ouvi casos de uma conhecida que entrou aos 18 anos na empresa, muito bonita e simpática chamava muita atenção. Um funcionário antigo da casa começou ir todos os dias no seu setor pra convidá-la pra sair. Ela não aceitava, então ele começou a fazer chantagem falando que iria dar um jeito de tirar ela da empresa (R4).

O primeiro excerto evidencia um processo que pode levar do assédio moral ao assédio sexual, corroborando com Freitas (2001). Já o segundo excerto, explicita a diferença entre convite e assédio, pois o segundo está relacionado a uma consequência inconveniente na relação de trabalho ("tirar ela da empresa"). Ainda sobre a relação entre assédio moral e sexual, observe o excerto:

Um colega de trabalho sabia que sua colega de trabalho [cometia atos ilícitos], [...] ele falou que se ela não fizesse sexo com ele, contaria pra todo mundo q ela tinha [cometido atos ilícitos] no local de trabalho. No outro dia ela me procurou e contou o que aconteceu, chorou muito. Quando vi ele chamando ela pra sair de novo, cheguei perto dele e disse.. Se vc não parar eu vou contar o padrinho dela $[. .$.$] e conto pra sua mulher. Com isso ele deixou ela em paz (R4).$

O assédio sexual pode conduzir ao assédio moral, pois havendo recusa à relação sexual (Ramos, 2013), o sujeito agressor expõe a vítima à violência psicológica para desestabilizá-la e isolá-la. As palavras de R4 (“contaria pra todo mundo", "chorou muito") explicitam essa possibilidade. Ainda nesse trecho de R4, é possível identificar uma exceção sobre a não intervenção de observadores, quando se trata de assédio sexual. Mendonça, Santos e Paula (2018) apontam como uma das lacunas dos estudos de assédio moral a carência de pesquisas sobre comportamento de colegas e supervisores perante uma situação de assédio. Portanto, esse achado pode ser um indicativo de comportamentos diferentes de observadores de assédio moral e sexual, podendo vir a ser uma questão na agenda de pesquisa. 


\subsection{Percepção sobre a própria vivência como vítima de assédio moral}

Os/as respondentes também foram questionados/as sobre já terem vivenciado alguma situação de assédio moral enquanto vítimas. Com características diferentes, o primeiro e o segundo relatos narram situações diversas que caracterizam o fenômeno do assédio moral vertical descendente.

Também já vivi e presenciei a experiência de querer estudar uma pós-graduação e precisar negociar a flexibilização do horário. Eu e meus colegas que fizemos isso, nos tornamos um problema e passamos a ser, constantemente lembrados, inclusive nas avaliações de desempenho, do "peso" dessa demanda para os outros colegas e para o setor. [...] Na época, eu não sabia, mas hoje sei que o que vivi na época do meu mestrado foi uma prática continuada de assédio moral. [...]Primeiro, tive que ouvir um sermão que incluiu a frase: "para a [Alfa], não interessa ter mestres e doutores e sim, gente disponível para ela o maior tempo possível”. Questionei que se fosse assim, a própria [organização] não teria criado um auxílio financeiro com essa finalidade. Ao final, de uma exaustiva e constrangedora conversa, em que fui tratado/a como se estivesse pedindo um favor imoral à instituição e estivesse prejudicando todos os meus colegas por isso, ainda ouvi em tom de brincadeira, com direito à risadinha debochada e dedo apontado para mim: "então, faça esse curso direito para isso valer a pena, hein". Me senti humilhado/a. [...] Foi a época em que mais peguei atestados médicos e morria de medo desses atestados serem entendidos como folgas para estudar. Mesmo assim, para minha surpresa, tive pontos retirados da minha avaliação de desempenho [...] Quer dizer, fui punido/a por uma demanda que não surgiu e não era verdadeira, já que duas vezes fui demandado/a a trabalhar à tarde e faltei de aula. [...] No entanto, me senti extremamente pressionado/a a sempre terminar tudo cedo, ser melhor do que todos os meus colegas no meu trabalho e terminar o mais rápido possível meu mestrado, tanto que fui o/a primeiro/a da minha turma a defender minha dissertação. Detalhe é que minha pesquisa foi sobre [um tema de interesse para organização] (R2).

Nesse trecho, percebe-se uma característica do fenômeno assédio moral nessa organização do Legislativo que não foi evidenciada em pesquisas realizadas em universidades e Poder Judiciário: o fato do trabalhador desejar estudar e isso ensejar atos hostis. Em outras organizações públicas, foram apontadas diversas situações decorrentes de abuso de poder. Sugerimos novamente que precisamos enfatizar não só o abuso de poder, mas o medo de perdê-lo.

Além do isolamento no setor, o excerto a seguir permite perceber também as práticas sutis de assédio (Fox \& Stallworth, 2005; Samnani, 2013) direcionadas a R5, como tratamento silencioso (ser ignorado pelos superiores), limitação da capacidade de expressar opiniões e sabotagem ao trabalho (boicote).

Outro processo que identifico como ligado ao assédio moral é o de isolamento dentro do setor e boicote com relação a trabalhos de maior proeminência institucional. A maioria dos "grandes trabalhos" que desenvolvi na organização foram a mim confiados por pedido ou pressão de outras áreas. Meus líderes, em vez de compreender esses chamados como reconhecimento de um membro de sua equipe, sempre se posicionaram com hostilidade e tentavam, sempre que possível, impedir que esse reconhecimento se concretizasse. [...] O silenciamento se deu de duas formas: tanto pelo meu afastamento da rotina de trabalho do setor (não sendo escalado para trabalhos que dissessem respeito à concepção do trabalho do setor e a seus processos), quanto pela efetiva não escuta (não sendo considerado como ouvinte em situações que os demais membros da equipe eram ouvidos, sendo silenciado/a nas poucas situações em que coloquei minha insatisfação com decisões ou processos equivocados). Entendo serem processos de assédio na medida em que tais ações minam sua 
confiança no setor, em seu superior hierárquico e na própria organização, criando um sentimento de hostilidade, desamparo, injustiça e indignação. Tais situações geram desconforto intenso em se permanecer no setor e a impossibilidade de denunciar tendo em vista o elevado grau de imprecisão. É difícil comprovar o boicote, é difícil comprovar o silenciamento, quando você é simplesmente ignorado/a. Porque os gerentes têm (entendem ter) a prerrogativa de ouvir quem quiser, de considerar quem quiser e jamais assumem que não te ouvem ou não te consideram por algum problema: a coisa é sempre tratada como algo corriqueiro, sem segundas intenções. $O$ ambiente torna-se tóxico porque na dinâmica desse tipo de assédio mais velado e sutil (embora sistemático), impera um tipo de relação dissimulada em que, publicamente, tudo parece transcorrer normalmente, mas, nas decisões que são tomadas, você se sente boicotado/a, silenciado/a e injustiçado/a (R5).

Um/a respondente demonstrou preocupação com o conceito dizendo em certo momento que a situação que viveu não seria assédio moral por não ter tido caráter de atos repetidos. Contudo, em outro momento, relata a seguinte situação:

Já sofri uma situação específica em que fui assediado/a moralmente por parte da assessoria de um [político] quando tive minha foto exposta no gabinete com a descrição "procura-se" depois de eu ter feito um post em um perfil em minha rede social virtual e que não agradou a este [político] (R1).

É importante ressaltar nesse excerto que, apesar de não haver reiteração de práticas, foi uma violência interpessoal (Pinto \& Paula, 2013). Além disso, demonstra a importância de se analisar a intensidade e não apenas a frequência (Wang et al, 2018). Acreditamos ainda que esse excerto traz uma peculiaridade do Poder Legislativo que é a proximidade dos trabalhadores da área administrativa com os políticos eleitos, uma vez que Câmaras Legislativas, Assembleias e Congresso Nacional se concentram em poucos prédios próximos entre si. Isso é diferente do que ocorre no Poder Executivo e Judiciário, instituições nas quais há uma pulverização de órgãos e prédios, nos quais se espalham trabalhadores em diversos setores, podendo haver mobilidade e distância dos mandantes de cargos eletivos. Assim, nos Poderes Executivo e Judiciário, o seu chefe imediato hoje pode ser seu colega de trabalho amanhã, o trabalhador pode mudar de setor, de órgão, talvez até de cidade/estado.

Já no Poder Legislativo, havendo essa proximidade dos membros do Poder, o servidor não está sujeito apenas à chefia imediata. Quanto mais mandatos eletivos na região, maior o número de "chefes" a que este servidor estará sujeito. Logo, em espaços com muitos "caciques" disputando poder, não é estranho se deparar com a cultura do "manda quem pode, obedece quem tem juízo" ou do "você sabe com quem está falando?", o que pode influenciar na cultura vivenciada na organização.

\subsection{Práticas que favorecem a ocorrência de assédio moral na organização}

Elementos da cultura na organização podem favorecer o assédio moral, como a cultura baseada na política, na vaidade, na hierarquia, no machismo, no silêncio e no excesso de 
discricionariedade nas regras. A cultura na organização pública do Poder Legislativo Alfa foi descrita nos próximos excertos.

Por se tratar de uma [organização] política, com uma cultura ainda baseada na hierarquia, no poder e na vaidade, aqui o ambiente ainda é muito propício para práticas de assédio (R1).

Eu acho que o principal problema é o excesso de discricionariedade nas regras, muitos critérios de aplicação das normas que estão nas mãos dos gerentes, ou seja, cada um interpreta como quer e isso, muitas vezes gera situações de conflito que desembocam em assédio, porque o servidor que questiona, por exemplo, interpretações subjetivas, passa a ser alvo de perseguições. Também é nefasta a cultura de bastidores da organização, ou seja, todo problema sério é resolvido nos corredores, com os amigos dos amigos, com quem tem proximidade com o poder, o caminho das sombras sempre se impõe aos instrumentos institucionais e, nesses arranjos, normalmente, os alvos de assédio são transferidos de setor e os assediadores continuam nos mesmos lugares, perpetuando práticas de assédio (R2).

A cultura machista e a hierarquia enraizada na organização. A discricionariedade do corpo gerencial predominantemente masculino. (R3).

Trabalho em um local que a política predomina [...] (R4).

A organização onde trabalho tem uma cultura de silêncio e dissimulação. É um ambiente onde se busca esconder problemas (seja menosprezando-os, seja silenciando as vozes que o expõem). Publicamente (seja para fora da organização, seja em espaços coletivos internos), a organização se vangloria, se enaltece e diminui os problemas que lhe são colocados. Quando se depara com situações em que suas idiossincrasias estão expostas, tenta silenciar, tratar das questões a portas fechadas, tomar decisões de maneira nada transparente. Tal cultura é um ambiente fértil para a prática do assédio moral [...] (R5).

Tais práticas demonstram que além de perfis individuais dos sujeitos, a cultura desenvolvida nas organizações também pode propiciar práticas que se tornem assédio moral ou violência interpessoal e, por isso, é importante compreender os aspectos que compõem a cultura dessa organização no Poder Legislativo. A cultura organizacional foi descrita como nefasta, machista, dissimulada, política, hierárquica, sem regras transparentes e com ênfase nos bastidores e nas portas fechadas, onde parece predominar o silenciamento e o caminho das sombras. Essas características são diferentes daquelas apontadas nos contextos universitários, dentre as quais a literatura destaca:

a) os aspectos culturais das instituições de ensino que gera contextos de permissividade e/ou conivência (Rodrigues \& Freitas, 2014);

b) certo descompasso entre discurso institucional preocupado com bem-estar e a ocorrência de práticas de abuso de poder e impunidade (Nunes, Tolfo \& Espinosa, 2019).

A intensidade negativa e repressora das palavras utilizadas para descrever a cultura organizacional da Alfa parece ser maior do que aquela existente na descrição da cultura nas universidades, mesmo que isso não identifique intensidades das práticas. Além disso, é preciso ressaltar que todas as práticas de assédio moral identificadas e analisadas nesta 
pesquisa ocorreram na forma vertical descendente, demonstrando um locus comum de existência do assédio moral e das violências interpessoais.

\subsection{Práticas de combate ao assédio moral na organização}

Os/as respondentes mencionaram os mesmos mecanismos de combate ao assédio moral na organização Alfa, como regulamentação de legislação, criação de núcleo para acolhimento de denúncias e de equipe mediadora e realização de campanhas informativas sobre o tema.

\footnotetext{
Existe uma norma interna que regulamenta as condutas com relação a denúncias e encaminhamentos e recentemente foi criado um Núcleo [Acolhedor] para acolhimento de denúncias e encaminhamentos institucionais (R1).
}

A [organização] aceitou, inclusive, fazer deste o tema da campanha de promoção da saúde de 2018, o que é um grande avanço. Enfim, estou otimista. (R2).

Freitas (2007) elencou diversos desafios para que se possa prevenir ou mesmo eliminar a ocorrência de assédio, dentre eles: vontade política das chefias, disposição em apurar e punir, sem exceções, tornar os mecanismos criados confiáveis, elencar profissionais imparciais para a atividade e prezar para que denúncias não fiquem sem respostas. Contudo, como as ações criadas são recentes, os/as respondentes não puderam fazer essa avaliação. A maioria não se posicionou diante das práticas criadas, havendo apenas um/a respondente manifestado pessimismo, conforme segue:

Onde a política manda não tem regras, tudo é mascarado pra não ser explícito. Quem já está na algum tempo na [organização] sabe o que realmente acontece. Não tem como combater o assédio no berço em que ele é criado (R4).

Há estudos em que foram sugeridas ações tanto individuais quanto institucionais para o combate ao assédio, desde capacitação de pessoas em cargos de direção, entendimento do conceito até mais transparência e diálogo nas ações (Nunes, Tolfo, \& Espinosa, 2019). Mas há também aqueles que focam na defesa de ações institucionais para coibir e combater o assédio (Nunes, Tolfo \& Nunes, 2014), como aconteceu neste estudo.

Por fim, há de se ressaltar que essa organização do poder legislativo precisa convencer o povo a continuar votando em seus representantes, o que não acontece em universidades e no Poder Judiciário. Assim, utilizando as palavras de R5, "publicamente (seja para fora da organização, seja em espaços coletivos internos), a organização se vangloria, se enaltece e diminui os problemas que lhe são colocados". Essa cultura organizacional parece refletir e reproduzir a forma como o jogo político é feito no país. 


\section{Considerações Finais}

Muitos trabalhos têm se dedicado a entender o assédio moral nas organizações. No caso das organizações públicas, o foco tem sido mais em universidades ou instituições do Poder Judiciário, tendo o Poder Legislativo sido deixado de lado nessas análises. Esta pesquisa teve o propósito de preencher tal lacuna, buscando compreender como o assédio moral era percebido por trabalhadores de uma organização pública do Poder Legislativo.

Atendendo aos objetivos, como principais achados de pesquisa, observa-se que o conceito de assédio moral entendido pelos trabalhadores, apesar de apresentar dimensões importantes como humilhação, constrangimento, subjugação e adoecimento, não apresenta a característica da reiteração de práticas. A própria percepção do assédio praticado na organização, por vezes, não possui essa dimensão, o que nos leva a defender que se reconheça a importância do conceito de violência, uma vez que os problemas causados às pessoas podem ser traumáticos mesmo que as práticas não aconteçam reiteradamente.

Outro achado importante se refere ao fato de os pesquisados relacionarem a cultura na organização com a ocorrência do assédio. A organização do Poder Legislativo estudada foi caracterizada como política, machista, hierárquica, dissimulada e com excessiva discricionariedade dos gestores, que seria propícia ao assédio.

Observamos também diferença de comportamento dos observadores, quando se trata de assédio moral e sexual. Essa diferença pode ser aprofundada em pesquisas futuras. Além disso, os/as respondentes manifestaram a dificuldade de se comprovar situações de silenciamento e boicotes, pois esse tipo de prática é sutil e não possui muitos elementos objetivos que auxiliem na sua identificação e comprovação, muitas vezes sendo defendida como discricionariedade da função do gestor. Portanto, é necessário refletir sobre as relações de poder que atravessam a constituição do sujeito gestor e os limites de suas funções.

Concluímos que práticas violentas sutis muitas vezes estão em um espectro de maior discricionariedade do gestor e podem ser confundidas com autonomia gerencial, tornando normalizadas ações que podem estar adoecendo trabalhadores. E que quanto maior essa discricionariedade, acompanhada por uma cultura organizacional repressora, maior é a dificuldade de comprovação do assédio moral que ocorre de forma sutil.

Para a realização desta pesquisa, e consoante com a literatura (Lewis \& Gunn, 2007), considera-se que houve barreiras para conseguir trabalhadores interessados em falar, pelo fato de o tema lidar com questões pessoais no ambiente de trabalho. Ademais, acredita-se que houve receio/medo de exposição. 
Como lacunas e sugestões para pesquisas futuras, sugere-se que seja investigada a relação entre assédio sexual e moral sob a perspectiva dos observadores e outras organizações que possuem a presença de políticos eleitos. Sugere-se também pesquisas sobre a relação entre diferentes culturas nas organizações públicas e a violência interpessoal. Acredita-se que uma pesquisa histórica possa auxiliar no entendimento de como essas práticas ocorriam e eram percebidas no passado em comparação com o presente.

Por fim, defende-se a inclusão do tema nos diversos cursos de formação de gestores, na tentativa de que as organizações possam ser vistas mais do que como ambiente de trabalho, mas como locus de vivência humana.

\section{Referências}

Bardin, L. (2009). Análise de Conteúdo. (5th ed.) Lisboa: Edições 70.

Batista, V. (2019). Assédio: queixas aumentam, mas processos diminuem. Correio Braziliense. Recuperado em 3 de abril, 2020, de: https://www.correiobraziliense.com.br/app/noticia/brasil/2019/05/06/internabrasil,753261/casos-de-assedio-moral-crescem-no-brasil.shtml

Boaventura, E. (2004). Metodologia de pesquisa: monografia, dissertação, tese. São Paulo: Atlas.

Câmara dos Deputados (2019). Câmara aprova punição para assédio moral no trabalho. Recuperado em 3 de abril, 2020, de: https:/www.camara.leg.br/noticias/553265-camaraaprova-punicao-para-assedio-moral-no-trabalho/

Chapadeiro, B. (2015). Relato de caso de assédio moral num hospital público de SP: entre o (des)serviço e a (in)justiça. In J. Gediel, E. Silva \& L. Mello (Orgs.). Estado, poder e assédio: relações de trabalho na administração pública. Curitiba: Kairós.

Corrêa, A. \& Carrieri, A. (2004). O assédio moral degradando as relações de trabalho: um estudo de caso no poder judiciário. Rev. Adm. Pública, 38(6), 1065-1084. Recuperado em 3 de abril, 2020, de http://bibliotecadigital.fgv.br/ojs/index.php/rap/article/view/6771

Fox, S. \& Stallworth, L. (2005). Racial/ethnic bullying: exploring links between bullying and racism in the US workplace. Journal of Vocational Behavior, 66, 438-456. https://doi.org/10.1016/j.jvb.2004.01.002

Freitas, M. (2001). Assédio moral e assédio sexual: faces do poder perverso nas organizações. Rev. adm. empres., 41(2), 8-19. http://dx.doi.org/10.1590/S0034-75902001000200002 
Freitas, M. (2007). Quem paga a conta do assédio moral no trabalho? RAE-eletrônica, 6(1), s/p. Recuperado em 3 de abril, 2020, de https://tinyurl.com/assedmor

Gediel, J. \& Mello, L. (2015). Estatuto jurídico do trabalho, formas de regulação e assédio moral. In J. Gediel, E. Silva \& L. Mello (Orgs.). Estado, poder e assédio: relações de trabalho na administração pública. Curitiba: Kairós.

Gonçalves, C. \& Meirelles, A. (2004). Projetos e Relatórios de Pesquisa em Administração. São Paulo: Atlas.

Harrington, S., Warren, S. \& Rayner, C. (2015). Human resource management practitioner's responses's to workplace bullying: cycles of symbolic violence. Organization, 22(3), 368-389. https://doi.org/10.1177\%2F1350508413516175

Heloani, R. \& Barreto, M. (2015). Assédio moral nas relações sociais no âmbito das instituições públicas. In J. Gediel, E. Silva \& L. Mello (Orgs.). Estado, poder e assédio: relações de trabalho na administração pública. Curitiba: Kairós.

Hirigoyen, M.-F. (2001). Assédio moral: a violência perversa no cotidiano. (2nd ed.) Rio de Janeiro: Bertrand Brasil.

Irigaray, H., Saraiva, L. \& Carrieri, A. (2010) Humor e discriminação por orientação sexual no ambiente organizacional. RAC-Eletrônica, 14, 890-906. Recuperado em 3 de abril, 2020, de https://www.scielo.br/pdf/rac/v14n5/v14n5a08.pdf

Leymann, H. (1996). The content and development of mobbing at work. European Journal of $\begin{array}{llll}\text { Organizational Psychology, } & \text { 5(2), } & \text { p. } & \text { 165-184. }\end{array}$ https://psycnet.apa.org/doi/10.1080/13594329608414853

Lewis, D. \& Gunn, R. (2007). Workplace bullying in the public sector: understanding the racial dimension. Public Administration, 85(3), 641-665. https://doi.org/10.1111/j.14679299.2007.00665.x

Mendonça, J., Santos, M. \& Paula, K. (2018). Assédio moral no trabalho: estado da arte e lacunas de estudos. Gestão e Regionalidade, 34(100), 38-55. https://doi.org/10.13037/gr.vol34n100.4399

Monteiro, D. (2013). E quando o salário é alto? Um estudo sobre o sofrimento e o adoecimento do servidor efetivo de uma organização pública do Estado de Minas Gerais. Dissertação de mestrado, Pontifícia Universidade Católica de Minas Gerais, Belo Horizonte.

Nunes, T. \& Tolfo, S. (2015). O assédio moral no contexto universitário: uma discussão necessária. Revista Ciências da Administração, 17(41), 21-36. https://doi.org/10.5007/2175-8077.2015v17n41p21 
Nunes, T., Tolfo, S. \& Espinosa, L. (2018). Assédio moral no trabalho: a compreensão dos trabalhadores sobre a violência. R.G.Secr.,GESEC., $\quad$ 9(2), 205-219. https://doi.org/10.7769/gesec.v9i2.629

Nunes, T., Tolfo, S. \& Espinosa, L. (2019). A percepção de servidores universitários sobre as políticas, ações e discursos institucionais sobre o assédio moral no trabalho. Organizações em Contexto, 15(29), 191-222. Recuperado em 3 de abril, 2020, de https://www.metodista.br/revistas/revistas-metodista/index.php/OC/article/view/8327

Nunes, T., Tolfo, S. \& Nunes, L. (2014). Assédio moral no trabalho em universidade sob a perspectiva dos observadores da violência. Revista de Carreiras e Pessoas, 4(2), 166176. https://doi.org/10.20503/recape.v4i2.20651

Pate, J., \& Beaumont, P. (2010). Bullying and harassment: a case of success? Employee Relations, 32(2), 171-183. https://doi.org/10.1108/01425451011010113

Petri, M., Severo, E. \& Guimarães, J. (2015). A produção científica brasileira sobre assédio moral entre 2009 e 2014. Espacios, 36(22), s/p. Recuperado em 3 de abril, 2020, de https://www.revistaespacios.com/a15v36n22/15362206.html

Pinto, R. \& Paula, A. (2013). Do assédio moral à violência interpessoal: relatos sobre uma empresa júnior. Cad. EBAPE.BR, 11(3), 340-355. https://doi.org/10.1590/S167939512013000300002

Pooli, A. \& Monteiro, J. (2018). Assédio moral no judiciário: prevalência e repercussões na saúde dos trabalhadores. Rev. Psicol., Organ. Trab., 18(2), 346-353. http://dx.doi.org/10.17652/rpot/2018.2.13516

Ramos, A. (2013). Assédio moral no ambiente laboral. Ambito Jurídico, 16(112). Recuperado em 3 de abril, 2020, de https://ambitojuridico.com.br/edicoes/revista-112/assedio-moral-noambiente-laboral/

Rodrigues, M. \& Freitas, M. (2014). Assédio moral nas instituições de ensino superior: um estudo sobre as condições organizacionais que favorecem sua ocorrência. Cad. EBAPE.BR, 12(2), 284-301. https://doi.org/10.1590/1679-39518275

Salin, D. (2003). Ways of explaining workplace bullying: a review of enabling, motivating and precipitating structures and processes in the work environment. Human Relations, 56(10), 1213-1232. https://doi.org/10.1177\%2F00187267035610003

Samnani, A.-K. (2013). "Is this bullying?" Understanding target and witness reactions. Journal of Management Psychology, 28(3), 290-305. https://doi.org/10.1108/02683941311321196 
Samnani, A.-K \& Singh, P. (2012). 20 years of workplace bullying research: a review of the antecedents and consequences of bullying in the workplace. Aggression and Violent Behavior, 17, 581-589. https://doi.org/10.1016/j.avb.2012.08.004

Sayer, A. (2007). Dignity at work: broadening the agenda. Organization, 14(4), 565-581. https://doi.org/10.1177\%2F1350508407078053

Soboll, L. \& Heloani, R. (2008). A origem das discussões sobre assédio moral no Brasil e os limites conceituais. In L. Soboll. Assédio moral/organizacional: uma análise da organização do trabalho. São Paulo: Casa do Psicólogo.

Speedy, S. (2006). Workplace violence: the dark side of organisational life. Contemporary Nurse, 21(2) 239-250. https://doi.org/10.5172/conu.2006.21.2.239

Vasconcelos, Y. (2015). Assédio moral nos ambientes corporativos. Cad. EBAPE BR, 13(4), 821-851. http://dx.doi.org/10.1590/1679-395141446

Wang, Q, Bowling, N. A., Tian, Q., Alarcon, G. M. \& Kwan, H. K. (2018). Workplace harassement intensity and revenge: mediation and moderation effects. Journal of Business Ethics, 151, 213-234. https://doi.org/10.1007/s10551-016-3243-2

Submetido em: 04.04.2020

Aceito em: $\quad 13.07 .2020$ 